\title{
From Offline Social Networks to Online Social Networks: Changes in Entrepreneurship
}

\author{
Yang SONG \\ University of Amsterdam Business School \\ Amsterdam, The Netherlands \\ y.songuva@gmail.com
}

The paper reviewed studies of entrepreneurship based on the emergency of online social networks. Similar to offline social networks, entrepreneurs' online social networks have their own unique characteristics. We first reviewed the offline network based research on entrepreneurship. Then we reviewed the studies of entrepreneurship in the context of online social networks including those focusing on topics of network structures and network ties. We highlighted online network communities based on the data collected from LinkedIn, Facebook and Twitter. Our research implies that both researcher and entrepreneurs are facing new opportunities due to the emergence of online social networks.

Keywords: Online social network, network, social capital, entrepreneurship

\section{1} Introduction

The nature of business and society is undergoing fundamental changes in light of the information age. Use of online communication is increasing and has become widespread. This trend also contributes to significant changes in internal and external organizational environments. Aggarwal identified the underlying relationship between technology and globalization, arguing that technology fosters globalization while globalization affects technological development, which leads to a new era of economy with a growing number of knowledge-intensive enterprises [1]. Emerging online networking has also opened the door for innovative companies to connect with each other and to operate more efficiently [20], [54]. The duality of financial crisis and numerous opportunities offered by the Internet has created an economic environment where the role of effective, knowledge-intensive businesses, so-called startups, have increased and become highly important. This trend is largely premised on the assumption that entrepreneurship has a positive effect on economic progress.

The role of entrepreneurship in economic development has been the focus of earlier studies. Entrepreneurship is a multidimensional concept because it can be defined at the level of firms, industries and nations and is of importance in modern economic development [63]. Globalization and advances in information and communication technology have brought about structural organizational change, hence, entrepreneurship has garnered a more important role in economic growth than ever before. Although it is obvious that not all entrepreneurial activities contribute equally to economic growth, knowledge-based enterprises might lead to the revitalization of the economy by influencing innovation, competition and industry dynamics. However, many early-stage businesses still face a lack of capital and background information about markets and competition that interfere with future opportunities. Investigating entrepreneurial success and survival of newly founded businesses, many researchers have come to the conclusion that social contacts - combined with social networks - are essential to thriving businesses [9], [11].

The popularity of online websites for networking is increasing and they provide a new platform for socialization and business. A recent study of online social media carried out by Comscore revealed that European Internet users spent an average of 27 hours online every month [14]. Looking more in depth, it has been found that social media sites are frequented by users on average of 
6.7 hours per month, thus making them the most-visited webpages [14]. Besides personal users, who mainly sign up to follow their friends, social media is also being leveraged by many businesses [39]. Previous studies mainly focused on social media as a marketing tool, but recently a growing number of entrepreneurs have realized its diverse potential [12],[64]. There has also been research to suggest that entrepreneurs with broader social networks are more likely to receive funding from investors and accomplish business development [5]. Furthermore, Hong argues that an increasing number of venture capitalists rely on social media sites and monitor promising startups' social-media efforts to assess the investment potential of each entity [37].

Due to the emergence of online social networks and social media, there are more opportunities for entrepreneurs. In this paper, we reviewed the development of online social networks and social media for entrepreneurs. We aim at providing researchers insights of entrepreneurship research based on online social networks. Moreover, we would like to generate useful recommendations for entrepreneurs' future business development.

\section{Offline social network}

Before we discuss the concept of online social networks, we would like to introduce the connection between entrepreneurship and offline networks. Networking is strongly related to entrepreneurship, which is "the process by which individuals - either on their own or inside organizations - pursue opportunities without regard to the resources they currently control" [59]. Entrepreneurs might encounter obstacle when they are about to use their resources. As a consequence, they have to take advantage of their existing social networks or try to establish new relationships to facilitate resource access and employment. Dubini and Aldrich defined social network as "patterned relationship between individuals, groups, and organizations", which plays an important role in entrepreneurial processes [16]. Brüderl and Preisendörfer found that broad and diverse social network is linked to entrepreneurial success [9]. A detailed research of the role of networks in the entrepreneurial context was conducted by Hoang and Antoncic [36], where in the entrepreneurs' network revealed three essential components: the content of network relationships, governance, and structure. Research of social network and entrepreneurship is changing due to the emergence of social media.

Network content describes the resources that flow and exchange between individuals and organizations [57]. On the one hand, relationships provide advice, information and emotional support to entrepreneurs, while on the other hand, networks can also lead to the exchange in resources [36]. Schonsheck suggests that the practice of networking is about making business friends, who can advance our business results: "it's not who, you know, it's who knows you" [55]. Networking aims to improve relations by "establishing, maintaining and expending the circle of business friends".

Relying on theoretical and empirical research, Hoang and Antoncic's study highlights positive outcomes of strong network structures and its influence on business development [36]. Network structure is defined as "the pattern of direct and indirect ties between actors" that varies in size, strength and diversity [16]. The types of entrepreneurial resources leveraged during the evolution of businesses have become a controversial topic. Individuals tend to rely on resources persistently during all venture stages. Although the type of information may change parallel with the venture phase, the development of ties is more important when considering the emergence of firms [18], [36].

Entrepreneurial ties are categorized according to the relation or agreement between two individuals. The difference between pairs of entrepreneurs is embedded in the strength of ties [16]. Dubin and Aldrich suggested two concepts of networks based on the intensity and diversity of 
relationships: personal (direct) and extended (indirect) networks [16]. The pattern of direct and indirect ties is defined as a network structure [36].

Considering the competitiveness of businesses, social networks and access to information are dominant factors of successful enterprises and appreciated by entrepreneurs. Burt highlighted that there are three kinds of capital, which lead to competitive advantage: financial, human and social capital [7],[11]. Social context and environment have been mentioned as a necessary entrepreneurial tool in other economic studies as well [9],[36]. Social capital exists in the relations among persons [13]. Unlike financial and human capital, social capital is owned jointly by parties. Furthermore investing time and effort in building social capital brings opportunities to transform human and financial capital to profit in return [11].

The importance of the concept of social capital for creating opportunities was emphasized by Aldrich and Zimmer [3]. They found positive relations between the extension of social networks and the scope of opportunities. Apart from opportunity formulation, networking also contributes to an innovative atmosphere that helps firms gain a better position on the market [16]. For example, MacMillan referred to network and contact building as the major factor of a firms' success [45]. Numerous studies examined the importance and significance of connections and stock of information between entrepreneurs. Shane and Venkataraman explained that only certain people recognize entrepreneurial opportunities, which they refer to as entrepreneurs' prior possession of information [56]. Since no one shares and receives entirely the same information at the same time, the probability of opportunity discovery and development are distinct and correlate with network building. It has been shown that startups that have larger informal communication networks - the weak ties increased their chance to overcome external shocks. The intensity of start-ups' communication correlates with the probability of continuance of businesses. It leads to the assumption that informal communication networks make it easier to obtain information that normally would require years [52]. Baum, Calabrese and Silverman also came to a similar conclusion during their research analysing how startup's alliance network configuration affects their early performance [6].

Steier's and Greenwood supported the influence of social networks on development and evolution of financial networks within young companies [57]. They described a four-stage model of an angel investors' network development: (1) Locating sources and building network from contacts. (2) Strengthening strategic relationships. (3) Optimizing resources and developing relationships into multi-dimensional network. (4) Managing complex networks and making new ties to expand business.

Their study emphasized the value of ties, particularly the significance of weak ties that grow and change during the stages of network revolution and contribute to a higher probability of investment. To sum up, all the abovementioned studies focused on networking and establishing relationships offline. However, in the era of the Internet, the concept of networking has changed significantly. Online platforms have become a prevalent and key source of information sharing. This means that there is a new channel that supports establishing weak ties with individuals and organizations while also maintains existing relationships [20].

\section{The emergence of online social networks}

The concept of social networking has always been present as a result of interpersonal connections such as friendships, common interests or ideas. However, network building also started online due to the introduction of broadband Internet. Although the emergence of social media started two decades ago, it is still growing rapidly and giving increasingly innovative experience to users. Online social networking is undoubtedly a global phenomenon. 
Social networking sites (SNSs) were defined, analyzed and valued in former academic reviews [20]. Boyd and Ellison described social network sites as "web-based services that allow individuals to (1) construct a public or semi-public profile within a bounded system, (2) articulate a list of other users with whom they share a connection, and (3) view and traverse their list of connections and those made by others within the system [8]." Kaplan defined SNSs similarly, he also highlighted the opportunity of creating personal profile to connect and communicate with friends or colleagues by emails or quick messages [39]. Users' profiles can include any type of information, for instance photos, videos, audio files, and blogs. Online social networking sites enable the maintenance of existing relationships and also the formation of new connections.

Researches have questioned whether the Internet is weakening, transforming or enhancing our community. Furthermore scholars argued that the act of building social capital differs offline and online. Although the vast majority of them have positive views on the Internet's impact on social life, some scholars found negative outcome on relationships that result in weak social capital. Nie argued that Internet usage is an isolating activity and users are becoming more unsociable [49]. Their social interaction is decreasing, which might affect their social capital. According to Kraut [42], using Internet leads to a decline in social involvement and psychological well-being. Both scholars concluded that frequent Internet users are likely to be lonely and isolated that contribute to depression. However, many other relevant studies criticised the idea of "lonely crowd" and draw opposite conclusions [15],[20],[33],[61]. Even the follow up report of Kraut's controversial study refuted previous findings on online networking [43]. Hampton and Wellman examined the online networks of a local community [33]. Their results showed positive effect on the group's social interaction and social capital, thus online interactions filled the communication gaps of offline conversations [61]. Recent studies have also emphasized the importance of online networking for the formation of stronger weak ties [15], [61].

Online opportunities differ by the nature of existing relations. Haythornthwaite was one of the first researchers, who presented a study on how the strength of social ties differ offline and online [34], [35]. She found that the new medium of communication has positive impact on both weak and strong-tie networks. On one hand, online connections may strengthen and develop weak-tie relationships while at the same time broadening the opportunities of strongly tied pairs for communication. Beyond social ties she introduced another level of tie: latent ties. Latent social network ties are formed by computer or non-computer organizations which are "technically possible but not activated socially". Only social activity can transform these ties to weak ties. Donath and Boyd speculated that online social networking increases the number of weak ties a person can have due to cheap technology and heterogeneous networks [15]. Other studies also added findings about how new dimension of communication can contribute to growing weakly-tied networks and support community building [32],[50].

In contrast with changes in personal relationships, only a few studies have been carried out to analyze how business relationships modify as result of online networking. However, it is important to understand how entrepreneurs of the $21^{\text {st }}$ century use online social networking sites to support their businesses. In 2009, McKinsey conducted a survey on companies' use of Web 2.0 social media platforms [47]. It revealed measureable results, which stemmed from better interaction with followers and fans, and from increased awareness of companies' products. Significant relational benefits led to higher revenues and more innovative business outcome. Fischer and Reuber analyzed 12 entrepreneurs to give new insights into social media usage in business context. Their study identified a positive relationship between the 
intensity of entrepreneurs' social interactions through Twitter and advancement through effectuation processes [21]. Another study focused on the success factors of startups in Germany by looking at the social network structure of their founders. It revealed that online networking matters and certain structural properties of these networks contribute to firms' success [48].

\section{The structure of online social networks for entrepreneurs}

The structure of social networks has changed in the last few years due to the rise of the Internet, allowing a shift to online interaction between contacts on social network sites (SNS). "The nature of online interaction has evolved rapidly, most notably through the surprisingly swift rise of online social networks such as Facebook, Myspace and Twitter. While older forms of online social interaction such as e-mail seemed especially suited to support existing offline interaction structures, these newer online social networks allow users not only to interact with their own contacts, but also traverse the network by discovering the contacts of their own contacts [8]. Individuals and companies use online social network platforms for social interaction as well as for maintaining and expanding their professional networks. Consequently, many organizations have adopted the use of SNSs for purposes such as relationship building, information exchange and collaborative work. However, despite a growing number of studies of SNSs, their use in organizational contexts, particularly in the context of entrepreneurship, has been largely neglected. As we know, obtaining access to financial, social and other types of resources is crucial, and social network sites might be an important vehicle for obtaining such access.

Since more than $71 \%$ of the developed world is now online with two thirds of the U.S adult population using social network sites, a figure that has doubled in the last few years, it is not remarkable that individual's social networks are also growing [46]. The average online social network user has around 350 friends on the networking site. Many users have exponentially increased their network size and diversity by linking with old high school friends and new colleagues.

However, Burke mentions that by opening up the online social network for customers, suppliers, employees and distribution partners to communicate together with friends and family, the structure of the online social network is automatically changing compared to what previous offline social network could reach [10]. Specifically, social network sites differ from the offline communication methods, as these allow a relationship with thousands of users through one single feed, which allows for an efficient maintenance of a larger social circle [10]."'Online social networks seem especially suited for the creation of new connections that bridge social contexts and thus may have an upgrading effect on the divisions found in modern societies, divisions typically reinforced through certain patterns of offline interactions. Recent empirical research suggests that while online networks are firmly rooted in existing offline social networks, they are positively associated with various forms of bridging social capital [7],[20]." When forming bridges in social capital, one must make the distinction between which ties form the best unique bridges. This forming of bridges and tie strength brings us back to the Granovetter Network ties [27].

\section{Online social network ties}

Social networks have many dimensions. However the perfect proportion of weak and strong ties is an issue of debate when discussing network benefits [19],[7],[38],[44],[60]. As previously mentioned, Granovetter identifies that there are two types of ties as distinguished based on their strength: strong and weak ties [27]. $\mathrm{He}$ describes the two different ties by describing the situation of any randomly selected individual who has a collection of close friends whom are all closely linked to each other (strong ties), and can be described as a densely knot clump of a social structure 
[27]. However, this randomly selected individual also has accumulated a collection of acquaintances that barely know each other, or have no relations to each other. These are known as weak ties. "Each of these acquaintances is likely to have close friends in his own right and therefore to be enmeshed in a closely knit clump of social structure, but one different from the individual. The weak tie between the individual and his acquaintance, therefore, becomes not merely a trivial acquaintance tie but rather a crucial bridge between the two densely knit clumps of close friends [27]." The benefit of this crucial bridge is extremely important to recognize, because if these trivial acquaintances relationships did not exists, these social clumps would in fact not be connected at all. This means, that if certain individuals have a social network lacking weak ties, they will not be able to benefit from other social clusters around them and the resources they can provide.

Researchers have shown that strong and weak ties have different advantages in different contexts [5], [31], [41], [51]. An entrepreneur's social contacts are often informal and non-work related [11]. These informal contacts, such as family and close friends, can be seen as 'strong assets', and are mainly used for assistance, requests for confidential information and obtaining resources [41]. Family support can be a crucial resource in the context of entrepreneurship and small-business formation [9], [62]. Strong ties are described as enhancing firm performance directly through the building of trust, information transfer and joint problem-solving arrangements [60]. Entrepreneurs use their other contacts - the 'weak ties', in other words - to obtain information that they cannot obtain from 'strong assets' [26],[28].

The lack of access to unique social resources can cause an individual to be confined to learning only about thoughts, opinions, advice and news from their strong ties. "This deprivation will not only insulate them from the latest ideas and fashions but may put them in a disadvantaged position in the labour market [26]." Not just random individuals have a tendency to connect with similar individuals, Kim and Aldrich have also illustrated that entrepreneurs have a high tendency to favour formation of dense networks based on strong ties [40]. Simultaneously, other research concluded that similarly to strong ties, weak ties are not only beneficial in terms of acquiring resources; they also play a role in other key entrepreneurial processes such as spotting opportunities [4], [19] and gaining legitimacy [2]. The importance of these findings raises the question what is the significance of strong and weak ties and what are the essential performance benefits to having a diverse online social network. The debate is still out whether weak ties, strong ties or a combination of both leads to the highest level of performance and growth. The importance of strong ties has been stressed at emergence of start-ups [7], [9]. While other researchers, have argued that a high number of weak ties are essential in the start-up phase [30], [36],[58].

The difficulty with making the distinction of which ties are important in an entrepreneur's online social network is that ties can fluctuate according to importance throughout the different phases of a start-up. This supports the various studies of both scholars such as [7],[9] and Jack [38] about the importance of strong ties while also agreeing with Steier \& Greenwood on their importance of weak ties [30],[57].

The amount of research available on how to identify weak ties and strong ties is very small. Where there is a lot of research on the diversity of a social network and weak and strong ties in general, the actual characteristics on what makes a tie strong or weak are limited. The earliest research is from Granovetter [29]. He defines the strength of ties as the intensity and diversity of relationships. Specifically, the difference between strong and weak ties on the basis of four criteria: the frequency of contact, the emotional intensity of the relationship, the degree of intimacy, and the reciprocal commitments between the actors involved. 
However, this research is primarily based on the offline social network of an individual, therefore more research was needed to identify the connection between tie strength and the online social network.

Gilbert \& Karahalois were one of the first to employ a combination of sociology and computer science for creating an API (application programming interface) that uses Facebook tie strength variables in order to create a measurement tool that accounts for an $87.2 \%$ reliable calculation of tie strength[24]. They recruited 35 participants to rate the strength of a randomly selected subset of their Facebook friends (guarding against those with large networks dominating the results). On the friend's Facebook profile five tie strength questions are asked based on a Likert scale. Gilbert \& Karahalois [24] found seventy Facebook variables categorized into different predictable variables including intensity, intimacy, duration, reciprocal services, structural, emotional support and social distance to predict tie strength. This research shows that some Facebook variables can be used to predict tie strength between the survey participant and his/her network ties. The connection of tie strength and Facebook is an important assumption for this research. Their tie strength questions will therefore also be used in this research, however due to privacy settings the use of their 70 Facebook variables is not realizable.

Burke builds on the approach used by Gilbert \& Karahalois [10],[24]. However, her research focuses more on the fluctuations of network ties considering social network sites (SNS). In her work, the most important addition to this is how she analysed the relationship of tie strength and Facebook activity. The collection of her data is based on a name generator, which allows the participant to enter names compared to Gilbert \& Karahalois' random selection [24]. She conducted a survey which contained questions about participant relationships with up to eight Facebook friends.

Both Gilbert \& Karahalois and Burke introduce the concept of network ties and the bridges between survey participants and their network ties [10], [24]. However, it is important to note that unlike the offline social network, network ties and bridges are referred to differently in the online social network respectively as nodes and edges. A node is representative of a specific tie in the network of an individual, while an edge is the bridge or connection this node has with another node in the network. Both edges and nodes have the characteristic of weight, this is characteristic is important to our research since we will be making a distinction between strong and weak ties based on edge weight. This distinction between the weights of the edges is necessary in order to calculate the diversity of the network, which introduces the next topic of diversity.

In order to explicitly recognize the social network, the social network is defined as "a set of people (or organizations or other social entities) connected by a set of social relationships, such as friendship, co-working or information exchange [23]." When trying to analyse social networks, the approach used was the "social network approach that facilitates the study of how information flows through direct and indirect network ties, how people acquire resources, and how coalitions and cleavages operate. Social network analysts look beyond the specific attributes of individuals to consider relations and exchanges among social actors [23].” Typical resources that are used by a social network include "textual, graphical, animated, audio, or video-based media, for example support, knowledge, sharing information (news or data), discussing work, access to distribution channels, giving emotional support, or providing companionship [34], [35].

The structure of a social network is never fixed; they are the social context of businesses and can be activated according to the different needs of the business [11], [28]. As they entertain, plan for, and actually set up a firm, entrepreneurs call on their family and others in their networks for different kinds of help and support [53]. However, throughout the start-up phase the connections drawn upon by the entrepreneur are likely to 
change and this acknowledges the importance of the fluctuating structure of the social network. In order to understand the role of a network tie, we use a more recent network measurement called 'edge betweenness', which was suggested by Girvan and Newman [25]. Edge betweenness is a measure of a particular edge's importance in keeping a network connected, these edges are most 'between' communities [25]. We can intuitively understand the concept if we think of a network as a form of flow, such as traffic flow. If each node were a town and the edges roads, and there was traffic between all of the towns, then edge betweenness would be the amount of traffic on each 'road'.

Edge betweenness can be used to calculate the strength of a tie in a network, which reflects the connections between nodes in a network in terms of 'the amount of time, the emotional intensity, the intimacy (mutual confiding), and the reciprocal services which characterize the tie' [26]. While in typical graph theory, the existence of an edge is binary, Granovetter also identifies two types: strong and weak ties [26].

In a network graph, a tie with a person from another community is called a 'local bridge'. A local bridge is by definition a weak tie, as it is hard for two people from different communities to devote the necessary resources to strengthening their relationship. However, bridges to other communities prove to be a very valuable information source. While weak ties provide access to a large and diverse pool of information and resources, strong ties are built on the basis of trust. The more intimate relationship between people connected by strong ties makes them more likely to help each other. Krackhardt has shown that strong ties are especially valuable in turbulent environments, where change and uncertainty reign [41]. Nodes in the same group or community in a network are tightly connected through strong ties. The members of such a group have many mutual connections, and we call such a group a community. Different communities are connected to each other through weak ties.
In a network, the shortest paths between nodes run through the weak ties among communities. For example, if two communities are only connected through one weak tie, all of the shortest paths between members of the first group and members of the second group must include this edge. Therefore, edges with highest betweenness values are the weak ties of a network and the bridge between two communities. In order to discover the structure of the network and the communities in the network, the edges with the highest betweenness values can be removed until no edges are left [22], [25]. The components remaining are the different communities of the network.

\section{The communities in online social networks}

Previous studies have found that individuals benefit from having social ties that form a bridge between communities [17]. We assumed that entrepreneurs' online social networks share similar structures, and thus that they are part of the same communities on different online social networks. In order to detect the different communities in the different networks, we adopted Girvan and Newman's method [25]: the edge with the highest betweenness centrality was removed for graph partitioning purposes. Examining the overlapping connections within the NoN, this process quickly disconnected the wellconnected communities in the graph. We calculated the edge betweenness for all ties after we had removed the ties with the highest betweenness values.

We adopted the following algorithm to test the overlapping nodes among networks: first, we set the betweenness of each tie to 0 ; second, we found $\mathrm{k}$ shortest paths between ties for each pair of nodes in the network; third, we took the value of ' $1 / \mathrm{k}$ ' to be the betweenness value for each tie on the shortest path. The basic Givan and Newman method works according to the following: while there are edges in the graph, compute the betweenness of all edges and remove the edges with highest betweenness values [25]. 
This method starts out with the graph and then iteratively removes edges. The process splits up existing communities into smaller sub-communities until there are no edges in the graph. The end state of the graph is not particularly interesting, as it is always a graph without edges. However, the process can be stopped, for example, when a certain criterion is reached. The ties that were removed during our process were always the weakest ties. Well-connected cliques stayed connected the longest, while bridges between different groups of people were eliminated.

In order to study entrepreneurs' online social network communities, we designed an online survey to collect data on entrepreneurs' online social networks. The survey website used the official Application Programming Interface (API) to collect data from the different online social networks. We used the API of each of the online social networks we studied to extract the entrepreneurs' profile and network data. Using the official API, we were able to collect actual behavioural data on the entrepreneurs - including profile information and connection information from LinkedIn, Facebook and Twitter. In total we have 345 respondents, including both entrepreneurs and non-entrepreneurs, participated in our survey. We filtered out the non-entrepreneurs, leaving 286 participants for our analysis. Of the 286 entrepreneurs, 261 participants shared their LinkedIn data with us. We collected both the entrepreneurs' LinkedIn profile data and that of their connections, while 188 participants shared their Facebook data with us. In addition, we stored each entrepreneur's profile data and friend profile data from Facebook. Only 174 participants shared their Twitter network data with us. The Twitter connections are directed, with, on average, each entrepreneur following 396 others and being followed by 628.

As we can see from Figure 1, the graph describes the process of removal of the edges with highest betweenness from the Twitter's online social networks. The edges that survive in the graph have a higher chance of being in both LinkedIn and Twitter networks. Our removal process showed that $33 \%$ of the edges in the Twitter graph corresponded with edges in the LinkedIn graph. Removing Twitter edges using the betweenness centrality method raises the percentage of overlap with the LinkedIn network over the remaining edges.

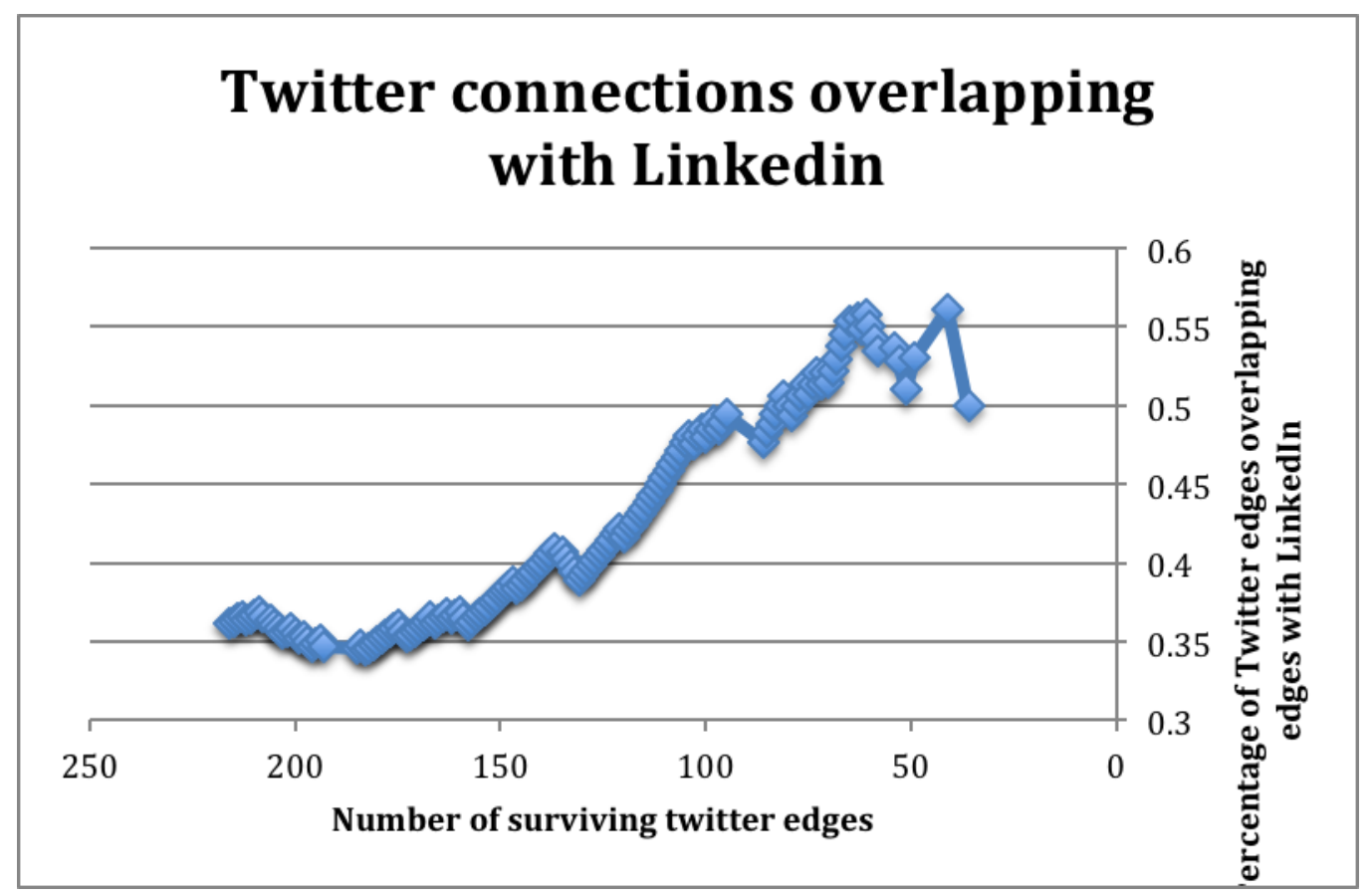

Fig. 1. Twitter connections overlapping with LinkedIn 
Similarly, we used the same methodology for Twitter and Facebook. As shown in Figure 2, the graph shows the process of removal of the edges with highest betweenness from Twitter. The edges that survive in the graph have a higher chance of being in both
Facebook and Twitter networks. Our results showed that $23 \%$ of the edges on Twitter overlapped with Facebook edges. Iterative removal of edges with the highest betweenness centrality raises the percentage of Twitter edges that overlap with Facebook.

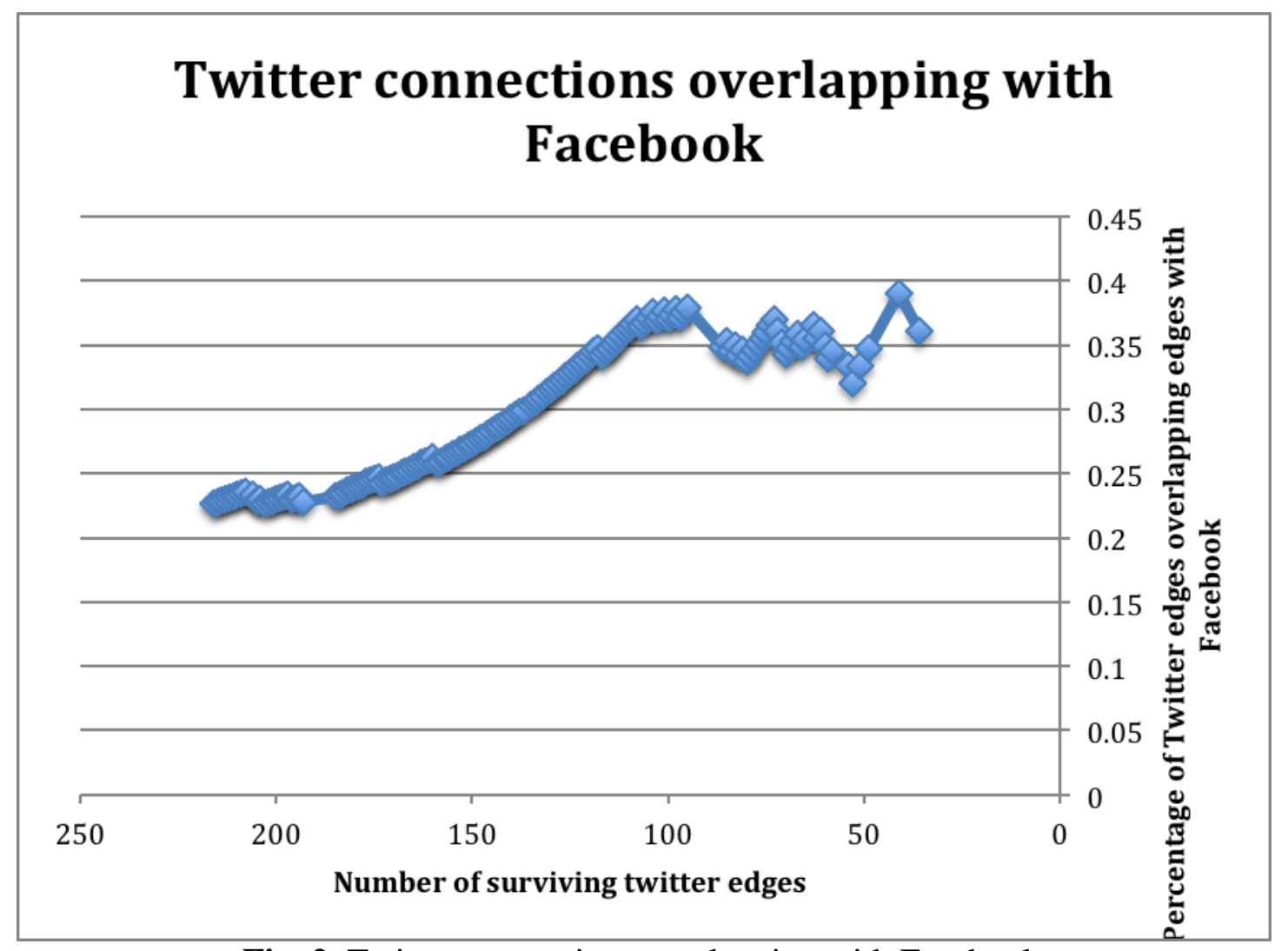

Fig. 2. Twitter connections overlapping with Facebook

The data is used to illustrate the structure of entrepreneurs' online social networks. Our findings suggest that entrepreneurs' networks are in fact networks of networks (NoNs), rather than single networks. Entrepreneurs use all three online social networks LinkedIn, Facebook and Twitter. Entrepreneurs' networks overlap at a range of between 19\% (Twitter-Facebook), 21\% (LinkedIn-Twitter) and 29\% (FacebookLinkedIn). The overlapping parts link groups of entrepreneurs' online social networks together and establish a NoN for entrepreneurs. By contrast, nonentrepreneurs use these networks separately, with limited overlapping among the three networks, at $2 \%, 2 \%$ and $8.4 \%$ respectively.
This finding suggests a high connectedness between entrepreneurs' online networks and the existence of weak ties in the entrepreneurs' NoN. Seminal work by Granovetter has demonstrated the importance of weak ties for providing access to a large and diverse pool of resources across networks and communities [26]. The role played by weak ties in the entrepreneurs' NoN is twofold: on the one hand, they serve as links between the different networks and facilitate the flow of information within and between the networks; on the other, the algorithm for the removal of weak ties helps us to uncover the network communities within the entrepreneurs' NoN. By comparing whether entrepreneurs share similar communities among networks, we 
were able to test whether entrepreneurs' online social networks overlapped with each other.

\section{Conclusions}

The findings of this paper will be twofold. On the one hand, we will explore the different purposes for which entrepreneurs make use of SNSs. Equally important to investigating the reasons for entrepreneurs to use these SNSs, is exploring why they do not use certain SNSs [8]. We will use these insights to understand why particular SNSs are more important for entrepreneurial startups than other SNSs. Additionally, these insights will be used to assess the relation between the use of SNSs and entrepreneurial performance.

On the other hand, we reviewed the development of research on entrepreneurship and online social network. This will give researchers and scholars new insights for the future research direction. To the literature on SNSs we contribute an understanding of how SNS is used in organizational contexts and more specifically in the context of entrepreneurial start-ups. To the literature on entrepreneurship we provide insights into the benefits of online social networks for entrepreneurial start-ups.

\section{References}

[1] Aggarwal, R., "Technology and Globalization as Mutual Reinforcers in Business: Reorienting Strategic Thinking for the New Millennium." MIR: Management International Review, Vol. 39, No.2, pp. 83-104,1999.

[2] Howard E. Aldrich and C. Marlene Fiol, "Fools Rush in? The Institutional Context of Industry Creation ", The Academy of Management Review, Vol. 19, No. 4 (Oct., 1994), pp. 645-670

[3] Aldrich, H. E. and Zimmer, C. "Entrepreneurship through social networks." In D. Sexton and R. Smilor (Eds.), The art and science of entrepreneurship, Cambridge, MA: Ballinger,1986.
[4] Ardichvili, A., Cardozo, R., \& Ray, S. "A theory of entrepreneurial opportunity identification and development." Journal of Business venturing,18(1), 105-123 ,2003.

[5] Baron, R. A. and Markman, G. D.. "Beyond social capital: the role of entrepreneurs' social competence in their financial success". Journal of Business Venturing, Vol. 18, Issue 1, 2003, pp. 4160.

[6] Baum, J., Calabrese, T. and Silverman, B.S. "Don't go it alone: alliance network composition and startups' performance in Canadian biotechnology", Strategic Management Journal, Vol. 21, No. 3, 2000, pp.267-294.

[7] Batjargal, B.. "Social capital and entrepreneurial performance in Russia: A longitudinal study". Organization Studies, 24(4), 2003, 535-556.

[8] Boyd, D. M. and Ellison, N. B.. "Social network sites: Definition, history, and scholarship". Journal of ComputerMediated Communication, Vol. 13, Issue 1, 2008, pp. 210-230.

[9] Brüderl, J. and Preisendörfer, P. "Network Support and the Success of Newly founded Businesses". Small Business Economics, Vol. 10, No. 3, 1998,pp. 213-225.

[10] Burke, M., Kraut, R., \& Marlow, C. "Social capital on Facebook: Differentiating uses and users." In Proceedings of the SIGCHI Conference on Human Factors in Computing Systems (pp. 571-580).2011, May, ACM.

[11] Burt, R.. "Structural holes: The social structure of competition". Cambridge, MA: Harvard University Press, 1992.

[12] Clark, M. and Melancon, J.. "The Influence of Social Media Investment on Relational Outcomes: A Relationship Marketing Perspective". International Journal of Marketing Studies, Vol. 5, No. 4, 2013,pp. 132-142.

[13]Coleman, J.. "Social capital in the creation of human capital". American Journal of Sociology, Vol. 94, Supplement: Organizations and 
Institutions: Sociological and Economic Approaches to the Analysis of Social Structure, 1998,pp. S95-S120.

[14] Comscore (2013). "2013 Europe Digital Future in Focus." Available at: http://www.comscore.com/Insights/Presen tations_and_Whitepapers/2013/2013_Eur ope_Digital_Future_in_Focus [accessed on 21 March 2014].

[15] Donath, J. and Boyd, D.. "Public displays of connection". BT Technology Journal, Vol. 22, No. 4, 2004,pp. 71-82.

[16] Dubini, P. and Aldrich, H. "Personal and extended networks are central to the entrepreneurial process". Journal of Business Venturing, Vol. 6, Issue 5, 1991,pp. 305-313.

[17] Eagle, N., Macy, M., \& Claxton, R.. "Network Diversity and Economic Development." Science, 328(5981), 2010, 1029-1031.

[18] Elfring, T. and Hulsink, W.. "Networks in entrepreneurship: The case of hightechnology firms". Small Business Economics, Vol. 21, Issue 4,2003, pp. 409-422.

[19] Elfring. T., \& Hulsink, W.. "Networking by Entrepreneurs: Patterns of TieFormation in Emerging Organizations." Organisation Studies, 28(12), 2007, 18491872.

[20] Ellison, N., Steinfield, C., and Lampe, C., "The benefits of Facebook "friends": Exploring the relationship between college students' use of online social networks and social capital". Journal of Computer-Mediated Communication, Vol. 12, No. 3, 2007,pp. 1143-1168.

[21] Fischer, E. and Reuber, A. R.. "Social interaction via new social media: (How) can interactions on Twitter affect effectual thinking and behaviour?" Journal of Business Venturing, Vol. 26, Issue 1, 2011,pp. 1-18.

[22] Freeman, L. C.. "A Set of Measures of Centrality Based on Betweenness". Sociometry, 40(1), 1977,35-41.

[23] Garton, L., Haythornthwaite, C. and Wellman, B., "Studying Online Social
Networks." Journal of ComputerMediated Communication, 1997.

[24] Gilbert, E., \& Karahalios, K. (2009, April). "Predicting tie strength with social media." In Proceedings of the SIGCHI Conference on Human Factors in Computing Systems, April 2009, pp. 211220. ACM.

[25] Girvan, M., \& Newman, M. E. J. (2002). Community structure in social and biological networks. Proceedings of the National Academy of Sciences, 99(12), 7821-7826.

[26] Granovetter, M.. "The Strength of Weak Ties". American Journal of Sociology, 78(6), 1973,1360-1380.

[27] Granovetter, M.. "The strength of weak ties: A network theory revisited". In P. V. Marsden \& N. Lin (Eds.), Social structure and network analysis, 1983, pp. 105-130. Beverly Hills, CA: Sage.

[28] Granovetter, M.. "Economic actions and social structure: The problem of Embeddedness". American Journal of Sociology, 1985,91(3), 481-510

[29] Granovetter, M.. "Getting a job: A study of contacts and careers". University of Chicago Press, 1995.

[30] Greve, A. and Salaff, J. W.. "Social Networks and Entrepreneurship". Entrepreneurship Theory and Practice, Vol. 28, Issue 1, 2003, pp. 1-22.

[31] Hansen, M. T.. "The Search-Transfer Problem: The Role of Weak Ties in Sharing Knowledge across Organization Subunits". Administrative Science Quarterly, 44(1), 1999,82-111.

[32] Hampton, K. N.. "Grieving for a lost network: Collective action in a wired suburb". The Information Society: An International Journal, Vol. 19, Issue 5, 2003, pp. 417-428.

[33] Hampton, K. and Wellman, B.. "Neighboring in Netville: How the Internet supports community and social capital in a wired suburb". City \& Community, Vol. 2, Issue 4, 2003, pp. 277-311.

[34] Haythornthwaite, C.. "Strong, weak, and latent ties and the impact of new media". 
The Information Society, Vol. 18, Issue 5, 2002, pp. 385-401.

[35] Haythornthwaite, C.. "Social networks and Internet connectivity effects". Information, Communication \& Society, Vol. 8, Issue 2, 2005, pp. 125-147.

[36] Hoang, H. and Antoncic, B.. "Networkbased research in entrepreneurship - A critical review". Journal of Business Venturing, Vol. 18, No. 2, 2003,pp. 165187.

[37] Hong, N. (2013). If You Look Good on Twitter, VCs May Take Notice. The Wall Street Journal, Available at: http://online.wsj.com/news/articles/SB100 0142412788732465940457849970227919 6058. [21 March 2014].

[38] Jack, S. L. "The Role, Use and Activation of Strong and Weak Network Ties: A Qualitative Analysis". Journal of management studies, 42(6), 2005,12331259.

[39] Kaplan A. M. and Haenlein, M.. "Users of the world, unite! The challenges and opportunities of Social Media”. Business Horizons, Vol. 53, Issue 1, 2010, pp. 5968.

[40] Kim, Phillip H. and Aldrich, Howard E., Social Capital and Entrepreneurship. Foundations and Trends in Entrepreneurship, Vol. 1, No. 2, p. 64, July 2005. Available at SSRN: http://ssrn.com/abstract=939776

[41] Krackhardt, David. "The Strength of Strong Ties: The Importance of Philos in Organizations." Networks and Organizations: Structure, Form, and Action, Harvard Business School Press, Boston, Mass., Nohria, Nitin \& Robert Eccles (eds.), 1992, pp. 216-239.

[42] Kraut, R. E., Patterson, M., Lundmark, V., Kiesler, S., Mukhopadhyay, T. and Scherlis, W. "Internet paradox: a social technology that reduces social involvement and psychological wellbeing?" American Psychologist, Vol. 53, No. 9, 1998, pp. 1017-1031.

[43] Kraut, R., Kiesler, S., Boneva, B., Cummings, J., Helgegson, V. and Crawford, “A.. Internet paradox revisited". Journal of Social Issues, Vol. 58, Issue 1, 2002, pp. 49-74.

[44] Lechner, C., Dowling, M., \& Welpe, I.. "Firm networks and firm development: The role of the relational mix". Journal of Business Venturing, 21(4), 2006, 514-540.

[45] MacMillan, I. C.. "The politics of new venture management". Harvard Business Review, November-December, 1983, pp. 8-16.

[46] Madden, M., \& Zickuhr, K.. "65\% of online adults use social networking sites". Pew Internet \& American Life Project, 2011, 1-14.

[47] McKinsey \& Company (Bughin, J., Chui, M. and Miller, A.). "How Companies are benefiting from Web 2.0.: McKinsey Global Survey Results". September, 2009 McKinsey Quarterly.

[48] Nann, S., Krauss, J., Schober, M., Gloor, P. A., Fischbach, K. and Führes, H.. "The Power of Alumni Networks Success of Startup Companies Correlates with Online Social Network Structure of its Founders". MIT Sloan School Working Paper, 2009, 4766-10, Cambridge, MA.

[49] Nie, N. H.. "Sociability, interpersonal relations, and the Internet: Reconciling conflicting findings". American Behavioral Scientist, Vol. 45, No. 3, 2001, pp. 420-435.

[50] Pinkett, R.. "Community technology and community building: Early results from the Creating Community Connections Project". The Information Society: An International Journal, Vol. 19, Issue 5, 2003, pp. 365-379.

[51] Podolny, J. M., \& Baron, J. N.. "Resources and Relationships: Social Networks and Mobility in the Workplace". American Sociological Review, 62(5), 1997, 673-693.

[52] Raz, O. and Gloor, P.A. "Size really matters: New insights for start-ups' survival". Management Science, Vol. 53, No. 2, 2007, pp. 169-177.

[53] De Rosenblatt, P. C., Mik, L., Anderson, R. M., \& Johnson, P. A.. "The family in business: Understanding and dealing with the challenges entrepreneurial families 
face", Jossey Bass Business and Management Series , 1985

[54] Ross, C., Orr, E. S., Sisic, M., Arseneault, J. M., Simmering, M. G. and Orr, R. R.. "Personality and motivations associated with Facebook use". Computers in Human Behaviour, Vol. 25, Issue 2,2009, pp. 578-586.

[55] Schonsheck, J.. Business Friends: Aristotle, Kant and Other Management Theorists on the Practice of Networking. Business Ethics Quarterly, Vol. 10, No. 4, 2000, pp. 897-910.

[56] Shane, S. and Venkataraman, S.. "The Promise of Entrepreneurship as a Field of Research". The Academy of Management Review, Vol. 25, No. 1, 2000, pp. 217226.

[57] Steier, L. and Greenwood, R.. "Newly created firms and informal angel investors: A four-stage model of network development". Venture Capital: An International Journal of Entrepreneurial Finance, Vol. 1, Issue 2, 1999, pp. 147167.

[58] Steier, L., \& Greenwood, R.. "Entrepreneurship and the evolution of angel financial networks". Organization Studies, 21(1), 2000, 163-192.

[59] Stevenson, H. H. and Jarillo, J. C.. "A paradigm of entrepreneurship:
Entrepreneurial Management”. Strategic Management Journal, Vol. 11, Special Issue: Corporate Entrepreneurship, 1990, pp. 17-27.

[60] Uzzi, B.. "Social structure and competition in interfirm networks: The paradox of embeddedness". Administrative science quarterly, 1997, 35-67.

[61] Wellman, B., Haase, A. Q., Witte, J. and Hampton, K.. "Does the Internet increase, decrease, or supplement social capital?" Social networks, participation, and community commitment. American Behavioral Scientist, Vol. 45, No. 3, 2001, pp. 436-455.

[62]Wellman, B., \& Wortley, S.. "Different Strokes from Different Folks: Community Ties and Social Support". The American Journal of Sociology, 96(3), 1990, 558588.

[63]Wennekers, S. and Thurik, R.. "Linking Entrepreneurship and Economic Growth". Small Business Economics, Vol. 1, Issue 1, 1999, pp. 27-55.

[64]Song, Y. \& Vinig, G., "Entrepreneur online social networks - structure, diversity and impact on start-up survival", Int. J. Organisational Design and Engineering, Vol. 2, No.2, 2012

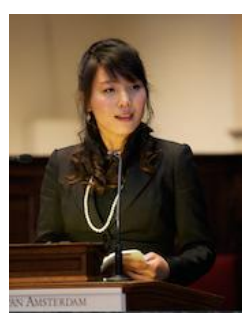

Yang SONG was born in Jilin, China on 9 February 1983. In 2005 she received her Bachelor's degree in Computer Science and Technology at Jilin University, China. In 2006 she started her Master's of Business Management at the School of Economics, Jilin University, completing it in July 2008. In October 2008 she received a scholarship from the Chinese Scholarship Council (CSC) and entered the $\mathrm{PhD}$ program in entrepreneurship at Amsterdam Business School, University of Amsterdam (UvABS). Yang Song successfully completed her $\mathrm{PhD}$ with a public defense on 30 November 2012 and was awarded the Doctor title from the University of Amsterdam. Dr Song has a lively interest in the field of entrepreneurship and innovation. Her research on entrepreneurship takes a network approach and is based on online social network data. In addition, she has a lively research interest in collecting and analyzing large amounts of network data. She is currently working on a number of projects, which involve analyzing entrepreneurs' behaviors using social network data, design thinking and service design for innovation decision process and determinants for entrepreneurs to raise crowd funding. 